\title{
Tissue Plasminogen Activator Alters Intracellular Sequestration of Zinc through Interaction with the Transporter ZIP4
}

\author{
Jaime Emmetsberger, ${ }^{1,2}$ Martine M. Mirrione, ${ }^{1,2}$ Chun Zhou, ${ }^{2}$ Monica Fernandez-Monreal, ${ }^{2}$ Mustafa M. Siddiq, ${ }^{2}$ \\ Kyungmin Ji, ${ }^{2}$ and Stella E. Tsirka ${ }^{1,2}$ \\ ${ }^{1}$ Program in Molecular and Cellular Pharmacology, ${ }^{2}$ Department of Pharmacological Sciences, Stony Brook University, Stony Brook, New York $11794-8651$
}

\begin{abstract}
Glutamatergic neurons contain free zinc packaged into neurotransmitter-loaded synaptic vesicles. Upon neuronal activation, the vesicular contents are released into the synaptic space, whereby the zinc modulates activity of postsynaptic neurons though interactions with receptors, transporters and exchangers. However, high extracellular concentrations of zinc trigger seizures and are neurotoxic if substantial amounts of zinc reenter the cells via ion channels and accumulate in the cytoplasm. Tissue plasminogen activator (tPA), a secreted serine protease, is also proepileptic and excitotoxic. However, tPA counters zinc toxicity by promoting zinc import back into the neurons in a sequestered form that is nontoxic. Here, we identify the zinc influx transporter, ZIP4, as the pathway through which tPA mediates the zinc uptake. We show that ZIP4 is upregulated after excitotoxin stimulation of the mouse, male and female, hippocampus. ZIP4 physically interacts with tPA, correlating with an increased intracellular zinc influx and lysosomal sequestration. Changes in prosurvival signals support the idea that this sequestration results in neuroprotection. These experiments identify a mechanism via which neurons use tPA to efficiently neutralize the toxic effects of excessive concentrations of free zinc.
\end{abstract}

\section{Introduction}

Zinc is an abundant trace element in the body, existing either bound to proteins or as a free ion. Bound to proteins zinc is an essential component of enzymes and transcription factors (Choi and Koh, 1998). In the CNS glutamatergic neurons contain free zinc packaged in vesicles with neurotransmitters and acts as neuromodulator (Frederickson et al., 2006a). Loss of zinc homeostasis results in adverse effects. During temporal lobe epilepsy (TLE), when there is an imbalance between excitatory and inhibitory neurotransmission in the hippocampus (Sloviter et al., 1996; Coulter, 2000; Walker et al., 2002), excess glutamate and zinc are released resulting in increased neuronal firing rates (Cornford et al., 2000; Kornblum et al., 2000; Millan et al., 2001; Mirrione et al., 2006) disinhibiting the dentate gyrus (DG) and

Received Dec. 17, 2009; revised Feb. 1, 2010; accepted Feb. 8, 2010.

This work was partially supported by National Institutes of Health Grant R01NS42168 and an American Heart Association Established Investigator Award to S.E.T., and National Science Foundation/3MT Integrative Graduate Education and Research Training support to J.E. and M.M.M. We thank Dr. Kyungmin Ji and Erin Rasco for teaching us how to use the hippocampal slice culture system, and Dr. Michael Frohman for critical editing of the manuscript, as well as Dr. Guangwei Du and members of the Tsirka-lab for discussions through the course of the experiments. We also thank the Frohman and the Colognato laboratories for sharing antibodies with us. We are grateful to Drs. G. K. Andrews and J. Dufner-Beattie for providing the mZIP-HA plasmids.

M.M.M. and C.Z. contributed equally to the work.

Correspondence should be addressed to Stella E. Tsirka, BST8-192, Department of Pharmacological Sciences, Stony Brook University, Stony Brook, NY 11794-8651. E-mail: stella@pharm.stonybrook.edu.

M. M. Mirrione's present address: Medical Division, Brookhaven National Laboratory, Upton, NY 11973; C. Zhou's present address: Human Genome Sequencing Center, Baylor College of Medicine, One Baylor Plaza, Houston, TX 77030; M. M. Siddiq's present address: Biological Sciences, Hunter College, New York, NY 10065; M. FernandezMonreal's present address: Centro de Biología Molecular "Severo Ochoa," Consejo Superior de Investigaciones Científicas, Universidad Autónoma de Madrid, Madrid 28049, Spain.

DOI:10.1523/JNEUROSCI.6250-09.2010

Copyright $\odot 2010$ the authors $\quad 0270-6474 / 10 / 306538-10 \$ 15.00 / 0$ spreading of the seizure (Sutula et al., 1986; Lothman et al., 1992). Zinc is released from mossy fibers (DG granule neuron axons) to facilitate the recruitment of DG cells into synchronized activity (Timofeeva and Nadler, 2006). Mossy fiber terminals were estimated to release $\sim 300 \mu \mathrm{m}$ chelatable zinc (Klitenick et al., 1983) under pathological conditions, such as epilepsy (Frederickson et al., 1988). Frederickson et al. (2006b) indicated that fluorimetrically measured zinc release in brain slices showed transient "puffs" that reached the 10-30 $\mu \mathrm{M}$ range. Since these concentrations were averaged over a spatial area larger than a synaptic cleft, the concentration was potentially much higher there. In nonstimulated extracellular space (e.g., CSF) $\sim 20 \mathrm{~nm}$ zinc were quantified. Excessive synaptic zinc release, intrahippocampal zinc injections or zinc deficiency can cause partial and secondarily generalized seizures (Pei and Koyama, 1986) and contribute to selective neuronal death (Suh et al., 2001). Excitotoxicity can also result in elevated levels of zinc release.

Another secreted factor that modulates seizure activity is the serine protease tissue plasminogen activator (tPA). tPA-deficient mice $\left(\mathrm{tPA}^{-/-}\right)$display resistance to pharmacologically induced seizures and are protected from excitotoxic death (Tsirka et al., 1995). Thus, both zinc and tPA promote epileptic outcomes and neurodegeneration. Nonetheless, tPA reduces neuronal death caused by zinc release during seizures (Kim et al., 1999; Siddiq and Tsirka, 2004), and, compared with wild-type mice, $\mathrm{tPA}^{-1-}$ mice exhibit increased seizure severity when zinc is exogenously introduced (Siddiq, 2003). We hypothesized that tPA is protective against excess zinc release, and demonstrated that tPA promotes facilitated import of zinc back into neurons (Siddiq, 2003). However, zinc did not accumulate in the neuronal cytoplasm, 
which would trigger cell death; instead, it was sequestered subcellularly.

Secreted zinc can enter into the postsynaptic neurons via $\mathrm{Ca}-\mathrm{A} / \mathrm{K}$, voltage-sensitive calcium channels (VSCC) (Siddiq and Tsirka, 2004), or be imported via zinc transporter proteins, such as the $\mathrm{ZnT}$ and the Zrt, Irt-like Protein (ZIP) family of transporters (Liuzzi and Cousins, 2004). ZIP family members were characterized in yeast and rodent tissues, but not in the mammalian CNS.

We address here how tPA mediates controlled zinc import and where zinc localizes in neurons during tPA-mediated sequestration. tPA interacts with the zinc transporter ZIP4, triggering intravesicular zinc accumulation that results in neuroprotection.

\section{Materials and Methods}

Animals. Adult C57BL6 (wild-type, wt) and tPA-deficient $\left(\mathrm{tPA}^{-1-}\right)$ mice were used according to protocols approved by the Stony Brook University IACUC and the Division of Laboratory Animal Resources (DLAR). Kainate was injected into the hippocampus at the following coordinates from bregma: anteroposterior $-2.5 \mathrm{~mm}$, mediolateral 1.7 $\mathrm{mm}$, and dorsoventral $-1.6 \mathrm{~mm}$ (Tsirka et al., 1995). The animals were deeply anesthetized and killed by transcardial perfusion with PBS or 4\% paraformaldehyde in PBS for samples analyzed by RT-PCR or immunohistochemistry, respectively. The brain tissue was removed and sectioned in 20 $\mu \mathrm{m}$ sections on a Leica cryostat when used in immunohistochemistry.

Reverse transcriptase PCR. Trizol (Invitrogen) was used to extract total RNA from mouse brain tissues and reverse transcriptase PCRs (RTPCRs) were performed as previously described (Takimoto et al., 1999). Oligo dTTP was incubated with $1 \mu \mathrm{g}$ of total RNA at $65^{\circ} \mathrm{C}$ for $5 \mathrm{~min}$. cDNAs were then synthesized, as described in the Superscript TM II Transcriptase first strand synthesis protocol from Invitrogen. Two microliters of this RT reaction was used as a template in each $50 \mu \mathrm{l}$ total volume of PCR with forward and reverse primers (see below). PC reactions were performed using Sigma Taq polymerase. The following primer sets were used for PCR amplification: mZIP1 forward, $5^{\prime}$-cacagccaccatggggccct- $3^{\prime}$; mZIP1 reverse, $5^{\prime}$-cttagatttggacaaagaga-3'; mZIP2 forward, $5^{\prime}$-cttcttgggagcagggttgatgc- $3^{\prime}$; mZIP2 reverse, $5^{\prime}$-cgccactgtggcctgtagtcc- $3^{\prime}$; mZIP3 forward, $5^{\prime}$-cgcaccgctccaagaaggtcctgtccctctgc- $3^{\prime}$; mZIP3 reverse, $5^{\prime}$-gctcacggtcacagccaacttggccg- $3^{\prime}$; mZIP4 forward, 5'-agaagtcagcacctctacaaggaacgc-3'; mZIP4 reverse, $5^{\prime}$-gctggctcagacccagggtc- 3 '.

Primary neuronal cultures. Hippocampal neuronal cultures were prepared from embryonic day 17-19 (E17-19) mice as previously described (Rogove and Tsirka, 1998; Siao and Tsirka, 2002). These are pure hippocampal neuronal cultures where the glial contamination is $\sim 2-3 \%$.

Organotypic hippocampal slice cultures. Hippocampi were isolated from postnatal day $9 \mathrm{wt}$ and $\mathrm{tPA}^{-1-}$ mice and sectioned into $400 \mu \mathrm{m}$ slices. Slices were placed on a membrane insert (Millipore, Inc.) in media containing 50\% MEM, 25\% HBSS, 25\% normal horse serum and placed in an incubator with a $5 \% \mathrm{CO}_{2}$ humidified atmosphere at $34^{\circ} \mathrm{C}$. After $7 \mathrm{~d}$ in culture, slices were treated for $2 \mathrm{~h}$ with $50 \mu \mathrm{m}$ zinc in HBSS in which Fluozin-3 was added 30 min before washing the slices and fixing in $4 \%$ PFA in PBS for imaging.

mZIP4 stable cell lines. The mZIP4 cDNA was cloned into pCDNA3.1 tagged with HA (the mZIP plasmids were a generous gift from Drs G. Andrews and J. Dufner-Beattie, University of Kansas Medical Center). To establish mZIP4 stable cell lines, HA-tagged mZIP4 was transfected into HEK293 cells using Lipofectamine from Invitrogen followed by selection with $10 \mu \mathrm{g} / \mathrm{ml}$ puromycin. Isolated stable cells were then grown in DMEM with $10 \%$ FBS. As a negative control for subsequent experiments, HA-tagged angiotensin-receptor 1 was similarly transfected in HEK293 cells.

$t P A$ cloning and expression. The full-length wild-type mouse $\mathrm{TPA}$ cDNA was cloned in pMT/Bip/V5-His vector using AvaI and Pme I (gift from Dr. Dan Lawrence, University of Michigan, Ann Arbor, MI). tPA mutants were generated using the Quick Change Site-Directed Mutagenesis kit from Stratagene based on the wild-type mouse tPA sequence. The mutants were: Ser481 to Ala (generating catalytically inactive tPA), finger domain deletion (deleting the sequence between amino acids Arg10 and Cys46), growth factor domain deletion (deleting the sequence between amino acids Phe60 and Cys87), and kringle 2 domain deletion (deleting the sequence between amino acids Cys183 and Cys265). The tPA constructs were transfected into Drosophila S2 cells and stable clones were obtained following selection with $25 \mu \mathrm{g} / \mathrm{ml}$ Blasticidin. To induce tPA overexpression, copper sulfate was added to the S2 medium (Schneider's Drosophila Medium containing 10\% heat-inactivated FBS) to a final concentration of $500 \mu \mathrm{M}$. Three days after induction, the supernatants were collected and analyzed by Western blot (immunoblot) and zymography for the presence of the induced recombinant proteins.

Immunoblotting. Immunoblots were performed on total cell lysates of the mZIP4 HEK cells. Equivalent concentrations of total protein were resolved by SDS-PAGE. For quantitative analysis, membranes were preincubated with Odyssey blocking buffer (LI-COR Biosciences) in PBS (1:1), and probed with primary antibodies in Odyssey blocking buffer in PBS $+0.2 \%$ Tween 20. Primary antibodies included anti-HA (Sigma), anti-ZIP4 (Alpha Diagnostic International), anti-phospho p42/p44 (pERK1/2), anti-p42/p44 (total ERK1/2), anti-phospho p38 (p-p38), antitotal p38, anti-phospho SAPK/JNK (p-JNK), anti-SAPK/JNK (total JNK), anti-phospho AKT (p-AKT) and anti-total AKT (Cell Signaling Technology). Membranes were probed with anti-rabbit IR dye 800 (Rockland) and anti-mouse Alexa Fluor 680 (Invitrogen) diluted in PBS-T. The Odyssey Infrared Imaging System (LI-COR Biosciences) was used to detect the proteins of interest for quantification. Quantification was performed with the Odyssey application Software 2.1.

Immunoprecipitation. mZIP4 transfected HEK cells were preincubated with $10 \mu \mathrm{g} / \mathrm{ml} \mathrm{tPA}$ (Activase) for different time periods up to $30 \mathrm{~min}$ at $37^{\circ} \mathrm{C}$ followed by ice-cold PBS rinse, and lysed at $4^{\circ} \mathrm{C}$ in RIPA buffer that contained phosphatase inhibitors $(20 \mathrm{~mm}$ Tris- $\mathrm{HCl} \mathrm{pH} 7.5,100 \mathrm{~mm}$ $\mathrm{NaCl}, 10$ mm EDTA, 10\% glycerol, 1\% Triton X-100). Protein concentrations were measured using Lowry assay reagents (Bio-Rad Laboratories). Immunoprecipitation were performed using $0.1-1 \mathrm{mg}$ of cellular proteins. Lysates were precleared using $20 \mu \mathrm{l}$ of protein A/G beads for $2 \mathrm{~h}$ at $4^{\circ} \mathrm{C}$. The supernatant was incubated with anti-tPA, anti-HA, or antiZIP4 antibodies and protein A/G beads overnight at $4^{\circ} \mathrm{C}$. Beads were pelleted at $1000 \times g$ for $1 \mathrm{~min}$, washed in PBS, and resuspended in $1 \times$ SDS with or without $\beta$-mercaptoethanol and boiled to further detect the presence of the HA tag, or were analyzed without boiling for tPA activity by zymography, respectively. Antibodies used for immunoprecipitation analysis included anti-HA (Sigma H9658) and anti-tPA (Santa Cruz Biotechnology SC-5241, or American Diagnostica Inc.).

Detection of tPA activity by gel zymography. Ten percent polyacrylamideSDS gels were copolymerized with $3 \mu \mathrm{g} / \mathrm{ml}$ casein and $50 \mu \mathrm{g} / \mathrm{ml}$ plasminogen. After electrophoresis, the SDS was removed by incubating the gels with $2.5 \%$ Triton X-100 for 30 min. The gels were washed with $\mathrm{H}_{2} \mathrm{O}$ before incubating in $0.1 \mathrm{M}$ Tris $\mathrm{pH} 8.1$ overnight at room temperature, staining with Coomassie brilliant blue, and destaining until clear zones of lysis became visible (Siconolfi and Seeds, 2001). The gels were dried and scanned and the images processed using ImageJ.

Amidolytic assay. tPA activity was assayed as described previously (Andrade-Gordon and Strickland, 1986).

${ }^{65} \mathrm{ZnCl}_{2}$ overlay. ${ }^{65} \mathrm{ZnCl}_{2}$ overlay was performed as described previously (Serrano et al., 1988) with modifications. Briefly, tPA and various tPA domain mutants ( $\Delta$ growth factor and $\Delta$ finger) were analyzed via SDS-Page and transferred on a PVDF membrane. The PVDF membrane was soaked in $0.05 \%$ Tween 20 in PBS for $3 \mathrm{~h}$ at RT, followed by $2 \mathrm{~h}$ incubation in $10 \mathrm{~mm}$ Na PIPES, pH 6.9, $50 \mathrm{~mm} \mathrm{NaCl}$, and $0.5 \mathrm{~mm} \mathrm{MnCl}_{2}$ and $5 \mathrm{~mm}$ dithiothreitol. The membrane was then incubated overnight following the addition of $5 \mu \mathrm{M}{ }^{65} \mathrm{ZnCl}_{2}(1 \mu \mathrm{Ci} / \mathrm{ml})$, washed with the above buffer minus zinc for $1 \mathrm{~min}$, then two $30 \mathrm{~s}$ washes with distilled water, and finally air dried on filter paper and exposed for $2-4 \mathrm{~h}$ on Kodak XAR-5 film.

Immunocytochemistry/immunohistochemistry. Parental and mZIP4transfected HEK cells were plated on coverslips coated with $0.2 \%$ gelatin. Once the desired cell density was obtained, the cells were fixed on the coverslips with $4 \%$ paraformaldehyde for $10 \mathrm{~min}$ at RT and permeabilized with $0.1 \%$ Triton-100 in PBS for 10 min at RT. After blocking with goat serum, the cells were incubated overnight with anti-HA antibody (1:1000, Sigma) to detect ZIP4. For the experiments on ZIP4 localization following tPA treatment, the mZIP4-transfected HEK cells were pretreated with $10 \mu \mathrm{g} / \mathrm{ml} \mathrm{tPA}$ and with increasing concentrations of zinc (10 
$\mu \mathrm{M}, 50 \mu \mathrm{M}$, and $100 \mu \mathrm{M})$ for $2 \mathrm{~h}$. Cells were permeabilized and blocked, and actin and ZIP4 expression was detected with Alexa Fluor 488 phalloidin (1:1000, Invitrogen) and anti-HA antibody (1:1000, Sigma), respectively. AntiLAMP-1 (1:300, Cell Signaling Technology) was used as a lysosomal marker.

For immunohistochemistry $20 \mu \mathrm{m}$ sections of brain tissue through the hippocampus were used to visualize the expression of ZIP4 using an anti-ZIP4 antibody (1:100, Alpha Diagnostic International). Neurons were detected using anti-NeuN (1:500, Millipore Bioscience Research Reagents). A biotinylated anti-rabbit secondary antibody was used followed by anti-mouse Alexa Fluor 488 and Streptavidin-conjugated 555. Sections were mounted with Fluoromount-G plus DAPI and analyzed via fluorescent microscopy.

Zinc import assay. Cells were plated onto 96well plates the day before the assay. The cells were washed three times with prewarmed Locke's buffer ( $154 \mathrm{~mm} \mathrm{NaCl}, 5.6 \mathrm{~mm} \mathrm{KCl}, 3.6$ $\mathrm{mm} \mathrm{NaHCO}_{3}, 1.2 \mathrm{~mm} \mathrm{MgSO}_{4}, 5.6 \mathrm{~mm}$ glucose, $2.5 \mathrm{~mm} \mathrm{CaCl}_{2}, 10 \mathrm{~mm}$ HEPES, pH 7.5). A $5 \mu \mathrm{M}$ final concentration of FluoZin-3 cell permeant AM ester (Invitrogen) in Locke's buffer was added for $30 \mathrm{~min}$ to load the cells with FluoZin-3. This was followed by the addition of tPA to the cells. After a 15 min incubation period with tPA, zinc was added to the cells and incubated for $2 \mathrm{~h}$. The zinc import assay was terminated by washing the cells with Locke's buffer. To examine the intracellular zinc levels, cellular fluorescence was read at excitation $480 \mathrm{~nm}$ and emission $510 \mathrm{~nm}$ on a fluorescent plate reader. All results presented were performed at least in triplicate in 3-4 separate experiments. The data were analyzed by one-way ANOVA with the Bonferroni's multiple comparison test.

Two-photon microscopy. Primary neurons grown on coverslips in 6-well tissue culture plates. Zinc import assay was performed as above and the cells were fixed in $4 \%$ paraformaldehyde, $4 \%$ sucrose in PBS for $15 \mathrm{~min}$ at $37^{\circ} \mathrm{C}$. Cells were permeabilized in $0.25 \%$ Triton $\mathrm{X}-100$, blocked with $10 \%$ normal goat serum-PBS at $37^{\circ} \mathrm{C}$ for $1 \mathrm{~h}$, incubated with primary antibody for cytochrome $C$ (PharMingen, $\mathrm{BD}$ Biosciences) in $3 \%$ goat serum-PBS at $4^{\circ} \mathrm{C}$ for $24-48 \mathrm{~h}$, incubated with fluorescent secondary antibody goat anti-mouse Cy3 (Invitrogen) in PBS for 20 min, and mounted with Vectashield containing 4',6-diamidino-2phenylindole (DAPI) (Vector Laboratories). At least 4 cells in each group $(n=3)$ were imaged using a Zeiss 510 two-photon microscope, and representative cells from two separate experiments are shown.

$X$-ray fluorescence microscopy. Primary neurons were plated on 200 mesh formvar-coated London Finer gold grids (Electron Microscopy Sciences), which were further coated in PDL $(100 \mu \mathrm{g} / \mathrm{ml})$ and laminin $(50 \mu \mathrm{g})$. Following the zinc import assay, the cells were washed with PBS and fixed in $4 \%$ paraformaldehyde in PBS for 10 min. Residual PBS was removed by several washes in $20 \mathrm{~mm}$ PIPES, pH 7.2/200 mm sucrose, and the cells air dried. This method of cell fixation and preparation for x-ray fluorescence minimized disruption of metal ion topology (Glesne et al., 2006; Finney et al., 2007) and did not significantly alter typical cellular
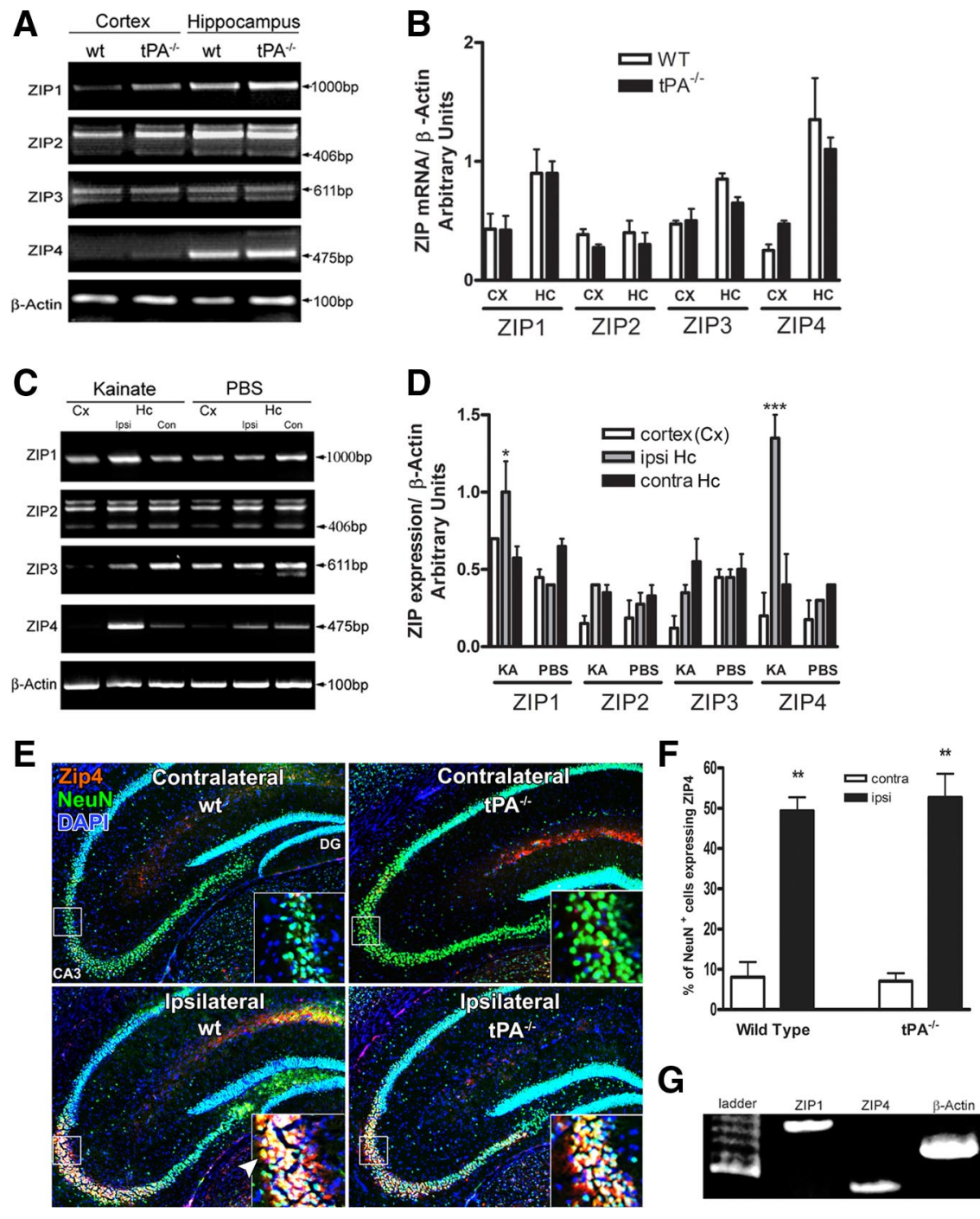

Figure 1. ZIP4 increases in expression in the hippocampus during excitotoxic events. $A$, Representative image of the expression of ZIP isoforms from wt and tPA ${ }^{-1-}$ cortices (CX) and hippocampi (Hc) was analyzed by RT-PCR. B, Quantification of ZIP isoform expression by densitometry using ImageJ software and comparison using one-way ANOVA. Error bars represent SEM $(n=3$ independent experiments). $C$, Wt and $\mathrm{tPA}{ }^{-1-}$ animals were injected unilaterally with kainate $(0.75 \mathrm{nmol})$ or PBS and the mRNA levels of the ZIP isoforms in the cortex and hippocampus (ipsilateral and contralateral to the injection site) were examined. D, Quantification of ZIP isoform expression after kainate injection by densitometry using ImageJ software and comparison using one-way ANOVA followed by Bonferroni's post hoc test. Error bars represent SEM where ${ }^{*} p<0.05$, ${ }^{* *} p<0.01$ ( $n=3$ independent experiments). $\boldsymbol{E}, \mathrm{Wt}$ and $\mathrm{tPA}{ }^{-1-}$ animals were unilaterally infused for $24 \mathrm{~h}$ with kainate $(\mathrm{KA} ; 0.75 \mathrm{nmol})$ into the hippocampus, following which the brains were fixed, sectioned, immunostained using anti-ZIP4 (red fluorescence) and anti-NeuN (green, a neuronal marker), and imaged by confocal microscopy. DAPI (blue) denotes nuclei. The CA3 region is marked. Boxed regions are shown at higher magnification in the panels in the inset. DG, Dentate gyrus. $\boldsymbol{F}$, Comparison of fluorescent intensity of ZIP/NeuN positive cells in the CA3 regions of the ipsilateral and contralateral sides. Quantification was performed by analyzing four $40 \mathrm{X}$ images of the $C A 3$ region and measuring the fluorescent intensity using AxioVision 4.6 imaging software. Error bars represent SEM, where ${ }^{* *} p<0.0098$ by one-tailed Student's t test ( $n=3$ independent experiments). Scale bar, $20 \mu \mathrm{m}$. G, Expression of ZIP1 and ZIP4 in cultured primary hippocampal neurons using RT-PCR. $\beta$-Actin was used as control. White arrowhead indicates cells on the ipsilateral side that are positive for nuclear DAPI and NeuN staining and cytoplasmic ZIP4 staining, which presents as yellow or white nuclei surrounded by a red halo. 
A

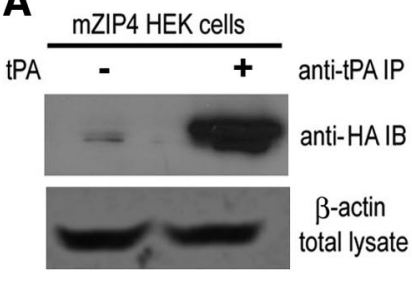

B

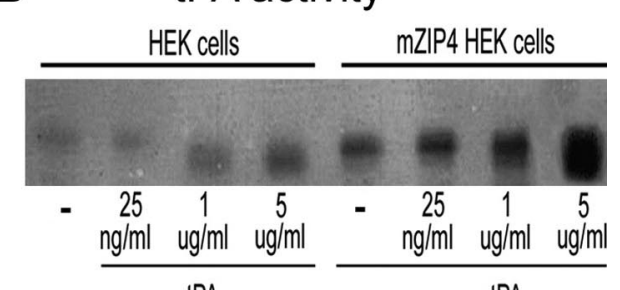

IPA

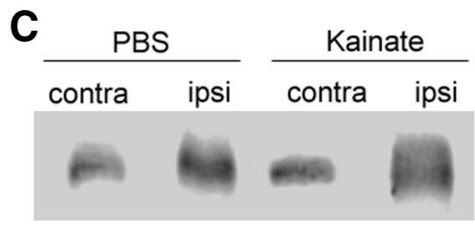

tPA

injected wt and $\mathrm{tPA}^{-1-}$ mice, especially in the CA3 subregion (quantification in Fig. $1 F)$, and its expression colocalized with the neuronal marker NeuN (Fig. $1 E$ ) and the microglial marker 5D4 (data not shown). Thus, neuronal expression of ZIP4 increases with neuronal activity, identifying ZIP4 as a potential candidate in the response to high level release of zinc during excitotoxicity, an event that also upregulates tPA (Qian et al., 1993).

\section{mZIP4 and tPA form a physical complex on the cell surface}

Since ZIP4 was the zinc transporter whose expression was affected to the greatest extent by neuronal injury, we focused subsequent investigation on this protein. We had reported previously that tPA increases import of zinc; this finding therefore suggested that IPA should mediate a direct or indirect effect on ZIP4 function. tPA is known to exert part of its actions through noncatalytic,

element UltraLE Ge-detector (Canberra). Image processing and determination of metal content within individual cells $\left(\mu \mathrm{g} / \mathrm{cm}^{2}\right)$ was performed with MAPS software (Vogt et al., 2003).

\section{Results}

\section{Neuronal activity modulates mZIP4 expression}

ZIP family members have been reported to be expressed in many tissues (Vogt et al., 2003). Using RT-PCR, we confirmed that mouse (m)ZIP1, 2, 3, and 4 are all expressed in the mouse brain (Fig. $1 A, C$ ). mZIP 2 and 3 exhibited similar levels of expression in the cortex and in the hippocampus, whereas mZIP4, and to a lesser extent, mZIP1, were expressed at higher levels in the hippocampus, which exhibits neuronal excitability during TLE. No significant differences in levels of expression of the mZIPs were observed for wild-type (wt) versus $\mathrm{tPA}^{-/-}$mice (Fig. $1 B$ ).

Since the physiological requirement for zinc transport could vary dramatically according to localized neuronal activity, and since relatively little is known about how the ZIPs are regulated, we hypothesized that cells might control their capacity for zinc import by using transcriptional mechanisms. We thus examined whether there were ZIP family members that changed their level of expression as a consequence of CNS stimulation. Wt (C57BL6) mice were injected unilaterally in the hippocampus with kainate, a glutamate analog that induces excitation and seizures, and the brains harvested for RT-PCR analysis $1 \mathrm{~d}$ later. No significant changes in expression level were observed for mZIP2, or 3 (Fig. $1 C)$; however, the levels of mZIP1 and 4 increased significantly in hippocampus on the side of excitotoxin injection (ipsilateral side), but not on the contralateral side, nor on the ipsilateral side after injection of PBS (Fig. 1D). Interestingly the change in ZIP4 expression was the most significant. ZIP1 expression has previously been associated with neurons (Belloni-Olivi et al., 2009). This finding was confirmed, as we used RT-PCR on isolated primary hippocampal neurons to evaluate the mZIP1 expression as well that of mZIP4 (Fig. $1 G$ ).

The change in expression of ZIP4 after stimulation was confirmed using immunohistochemistry with an anti-ZIP4 antibody (Fig. $1 E$; supplemental Fig. 1, available at www.jneurosci.org as supplemental material). Upregulation of ZIP4 expression was evident on the injected side of the hippocampus in the KA- protein-protein interactions involving cell surface binding partners such as annexin II (Siao and Tsirka, 2002). We thus began by exploring the possibility that tPA might physically interact with ZIP4.

To assess the interaction between ZIP4 and tPA, exogenous tPA was added to the cultured cells. We used $10 \mu \mathrm{g} / \mathrm{ml}$ tPA, a concentration which has previously been used and shown to abolish zinc-induced cell death (Kim et al., 1999). Control HEK293 cells and HEK293 cells stably expressing HA-tagged mZIP4 (supplemental Fig. 1, available at www.jneurosci.org as supplemental material) were cooled on ice and exposed to human tPA in culture medium for $5 \mathrm{~min}$. The cells were washed, lysed in RIPA buffer to preserve interacting protein complexes, immunoprecipitated using anti-tPA antibody, and immunoblotted using anti-HA antibody to detect coprecipitated HA-tagged ZIP4. In the absence of exogenously added tPA, very little ZIP4 was detected; in the presence of tPA, ZIP4 was robustly pulleddown (Fig. 2A). In the reverse experiment, the control and HAZIP4-expressing HEK293 cells were incubated with a range of concentrations of mouse tPA and immunoprecipitated with anti-HA antibody, following which tPA activity was measured using zymography (Fig. $2 B$; zymography was required because the anti-human tPA antibody does not recognize mouse tPA well). Larger amounts of tPA were pulled down from the lysates of ZIP4-expressing cells than from the control HEK 293 cells at every concentration of tPA used. Intriguingly, more tPA activity was present even in the sample in which no exogenous tPA had been added, indicating that endogenous tPA was being pulled down by the ZIP4.

To ascertain that the ZIP4/tPA interaction is physiologically relevant in vivo, wt mice were intrahippocampally injected with PBS or kainate and after $24 \mathrm{~h}$ their brains were harvested and lysed. ZIP4 was immunoprecipitated and the associated tPA activity was assessed via zymography. Higher levels of tPA activity associated with the immunoprecipitated ZIP4 were detected in the injected side (ipsi) after the kainate injection (Fig. 2C). These data indicate that tPA and ZIP4 form a physical complex on the cell surface, providing a possible mechanism through which tPA might facilitate ZIP4-mediated zinc import. 


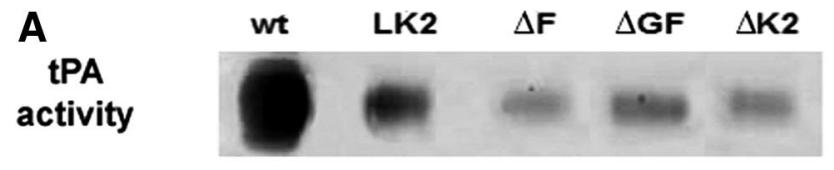

B
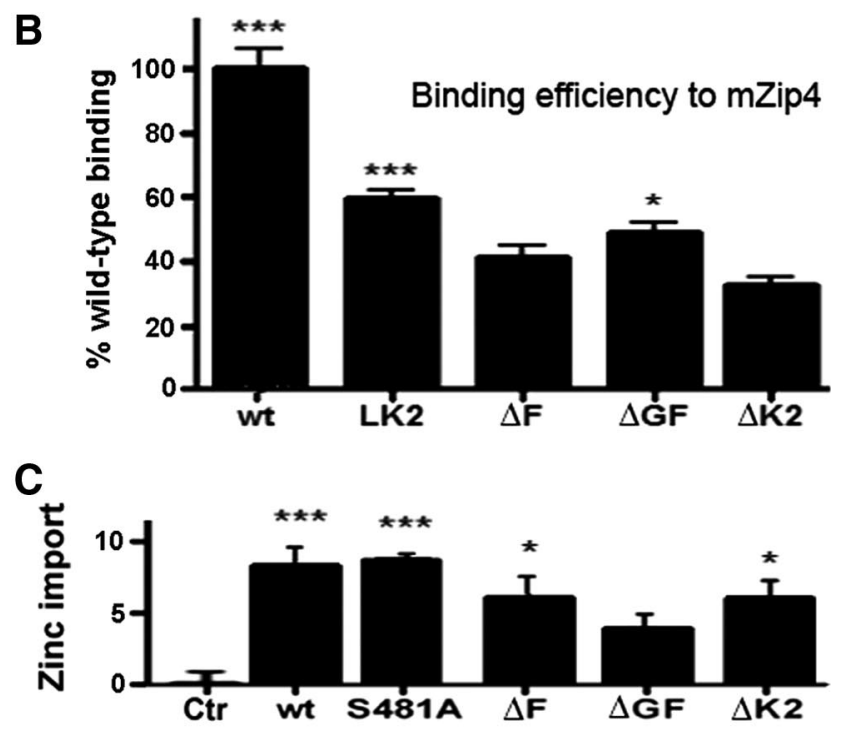

\section{Correlation between binding efficiency}

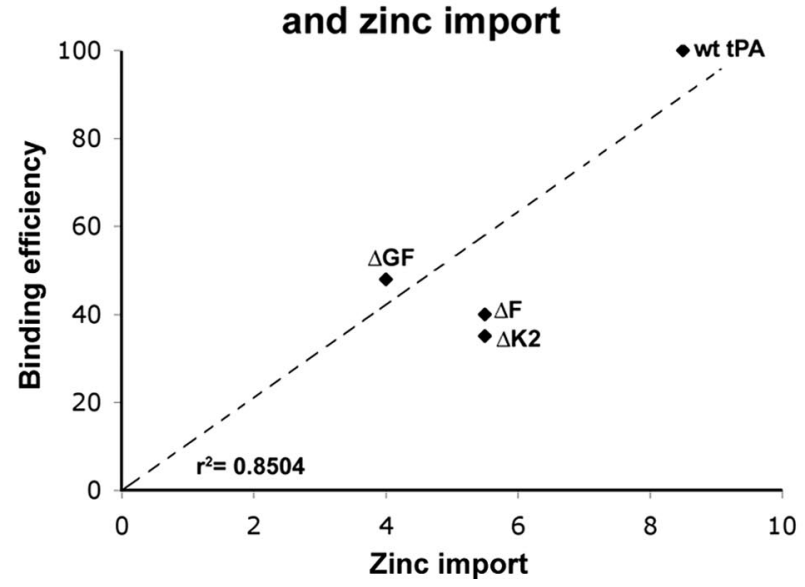

Figure 3. $\mathrm{TPA}$ protein domains important for ZIP4 physical and functional interaction. A, HA-mZIP4-expressing HEK293 cells were incubated on ice with $10 \mu \mathrm{g} / \mathrm{ml}$ wt tPA or varied tPA domain mutants, washed, lysed, immunoprecipitated with anti-HA, and assessed for PAA activity via zymography. LK2, Mutant encoding only light catalytic chain and second kringle domain; $\Delta \mathrm{F}$, mutant lacking finger domain; $\Delta \mathrm{GF}$, mutant lacking growth factor domain; $\Delta \mathrm{K} 2$, mutant lacking second kringle domain. $\boldsymbol{B}$, tPA zymographic activity was quantified by densitometry using ImageJ software. The inactive mutant S481A tPA was used as a negative control (data not shown) and its densitometric value (since it is catalytically inactive) was subtracted from the values of all the other recombinant proteins, following which the binding for each mutant was normalized to that observed for the wild-type protein. Error bars represent SEM where ${ }^{*} p<0.05,{ }^{* *} p<0.001$ by ANOVA followed by Bonferroni's post hoc test $(n=3$ independent experiments). C, HEK293 cells expressing mZIP4 were preloaded with FluoZin-3 and incubated with wt tPA, tPA domain mutants, or catalytically inactive (S481A). Ctr, Control mZIP4-HEK293 cells incubated with media that did not contain recombinant tPA. Zinc import was quantified by fluorometric analysis (ratio A480/A510). $D$, Correlation between zinc import and ZIP4 binding efficiency by different tPA recombinant proteins.

Domain analysis of the physical and functional interaction of tPA with ZIP4 and zinc

Given the physical association between mZIP4 and tPA, we next examined whether the interaction was mediated by a specific region of the tPA protein. $\mathrm{tPA}$ consists of five domains: a

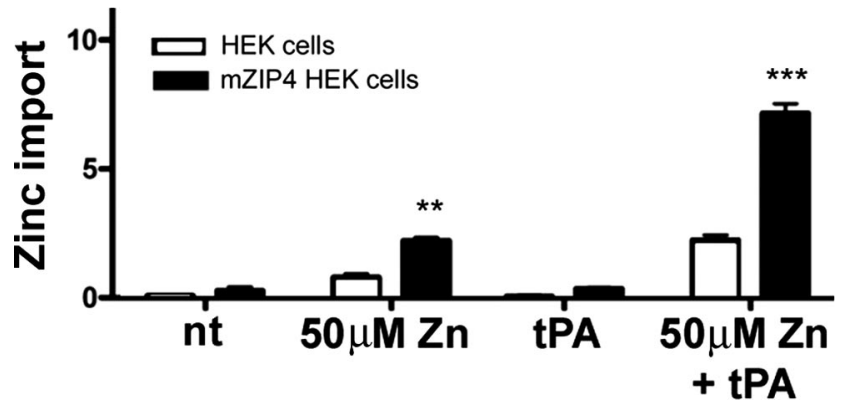

Figure 4. Zinc uptake is augmented in the presence of tPA. HEK cells and mZIP4-expressing HEK cells preloaded with FluoZin-3 were incubated with zinc in the presence or absence of 10 $\mu \mathrm{g} / \mathrm{ml}$ tPA. The amount of zinc uptake was quantified by fluorometry (ratio A480/A510).

fibronectin-3 finger domain (F) at the $\mathrm{N}$ terminus, followed by an epidermal growth factor (EGF)-like domain (GF), two kringle domains (K1 and K2) and a carboxy-terminal light (L) catalytic domain (van Zonneveld et al., 1986). We previously reported that the catalytic activity of tPA was dispensable for this pathway, since a catalytically inactive tPA mutant (S481A tPA) promoted zinc intracellular import just as well as the wild-type, catalytically active protein (Siddiq, 2003; Siddiq and Tsirka, 2004).

Recombinant tPA proteins lacking individual or multiple domains, all of which were catalytically active, were expressed and purified and assayed for the ability to be pulled-down in association with ZIP4. All of the mutant proteins demonstrated reduced binding, with deletion of the second kringle domain $(\Delta \mathrm{K} 2)$ having the greatest impact (Fig. $3 A, B$ ). As a negative control in this set of experiments HA-tagged Angiotensin Receptor 1 (AT1R) was used (transfected into HEK293 cells similarly to ZIP4). This protein was not found to interact with tPA nor to enhance zinc import (data not shown). The ability of the wildtype and mutant proteins to stimulate zinc import was then assessed. Wild-type and catalytically inactive S481A tPA facilitated zinc import with equal efficiency (Fig. 3C), in agreement with our previous results (Siddiq and Tsirka, 2004), and the mutant proteins were less effective. Surprisingly though, the mutant protein lacking the growth factor domain $(\Delta G F)$ was less potent than $\Delta \mathrm{K} 2$. The correlation derived between zinc import and ZIP4 binding by the different tPA recombinant proteins has a coefficient of 0.8504 (Fig. 3D).

An additional factor to consider, however, is that tPA not only binds ZIP4, but also binds zinc; thus the observed facilitation of zinc import could result either or both from increased zinc bound to the transporter, or to internalization of zinc bound to tPA. To address this issue, we next examined the ability of the mutant $\mathrm{tPA}$ proteins to bind zinc using a published ${ }^{65} \mathrm{ZnCl}_{2}^{-}$overlay assay. Relatively normal binding was observed for the $\Delta \mathrm{F}$, whereas all binding was lost for the $\Delta$ GF mutant (supplemental Fig. 2, available at www.jneurosci.org as supplemental material).

Together, these findings indicate that the ability of tPA to promote zinc import via interaction with ZIP4 depends both on the ability to bind to ZIP4 and independently on the ability to bind zinc.

Increased import of zinc in the presence of tPA is associated with changes in zinc and ZIP4 subcellular localization We previously demonstrated that the levels of intracellular zinc increase in neuronal cells in the presence of tPA (Siddiq, 2003; Siddiq and Tsirka, 2004). Examining this relationship using another approach, $\mathrm{x}$-ray spectroscopy revealed that the addition of $\mathrm{tPA}$ 

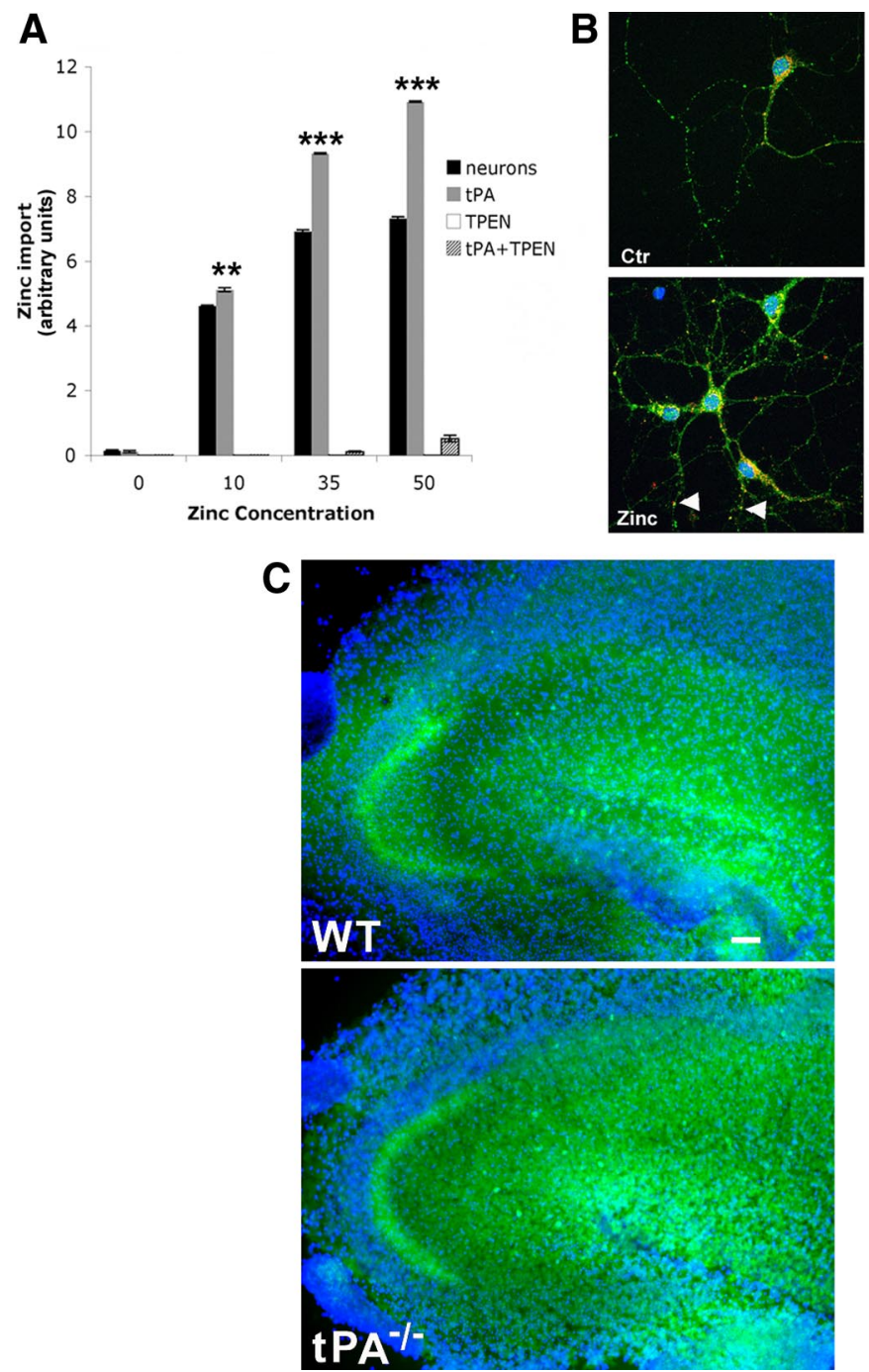

Figure 5. TPA enhances zinc uptake in hippocampal neurons. $A$, Hippocampal neurons loaded with FluoZin- 3 were incubated 0 $10,35$, and $50 \mu \mathrm{m}$ zinc and/or tPA (10 $\mu \mathrm{g} / \mathrm{ml})$. Quantification of intracellular zinc was performed by fluorometric analysis (A480/A510) at $2 \mathrm{~h}$, and the values are expressed as arbitrary units. The membrane-permeable zinc chelator TPEN was then added and the cells reimaged. The import of zinc is presented in arbitrary units. $\boldsymbol{B}$, Two-photon imaging of wt hippocampal neurons (naive, treated with tPA, with $50 \mu \mathrm{m}$ zinc, or with both zinc and tPA) loaded with FluoZin-3 (green) and counterstained against cyt $C\left(\right.$ red). Arrows indicate coincident fluorescence of FluoZin3 and cyt $C$. Error bars represent SEM, where ${ }^{* *} p<0.01,{ }^{* * *} p<0.001$ by two-way ANOVA followed by Bonferroni's post hoc test ( 4 neurons of each experimental condition were quantified from $n=3$ independent experiments). $C$, Organotypic hippocampal slices from wild-type and $\mathrm{PPA}^{-1-}$ mice treated with $50 \mu \mathrm{m}$ zinc and loaded with Fluozin-3 (green) to assess zinc uptake. Scale bar, $20 \mu \mathrm{m}$ ( $n=3$ independent experiments, 3 slices/experiment). The Fluozin-3 fluorescence intensity of the whole slice was quantified, divided by the slice surface area and was analyzed using AxioVision 4.6 image software. Wt slices exhibited 0.58 arbitrary units of fluorescence/surface area compared with 0.35 units for the $\mathrm{PAA}^{-1-}$ slices ( $p=0.2232$ by one-tailed Student's $t$ test).

to the culture medium for 30 min increased zinc uptake by $25 \%$ (from 4 to $5 \mu \mathrm{g} / \mathrm{cm}^{2}$ ) in the cytoplasm of wild-type hippocampal neurons, and by $250 \%$ (from 1 to $3.5 \mu \mathrm{g} / \mathrm{cm}^{2}$ ) in neurites, which have many presynaptic vesicles that can store zinc (supplemental Fig. 3, available at www.jneurosci.org as supplemental material). Additional measurements for other elements, such as phosphorus, sodium, calcium and potassium, were also obtained to confirm basic cellular viability and functions, and were found not to change (data not shown). This experiment confirmed our previous observations that $\mathrm{PA}$ facilitates the import of zinc into neurons, and adds the new observation that uptake is promoted primarily into neurites.

To extend this finding, HEK293 cells and ZIP4-expressing HEK293 cells were loaded with the fluorescent zinc reporter,

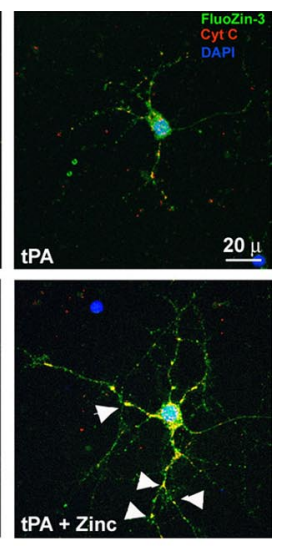

FluoZin-3, and exposed to $50 \mu \mathrm{M}$ zinc in the presence or absence of tPA. As shown in Figure 4, tPA increased zinc uptake in the mZIP4-expressing cells. Similar results were obtained with primary hippocampal neurons, which endogenously express mZIP4 (Fig. 5). The neurons were loaded with FluoZin-3 and incubated with increasing concentrations of zinc in the presence or absence of $10 \mu \mathrm{g} / \mathrm{ml} \mathrm{tPA}$. The levels of intracellular zinc (evident as change in the amount of fluorescence within the cells) increased when the cells were incubated with increasing concentrations of zinc, and a further increase was seen when tPA was also present (Fig. 5A). The increase in fluorescence was specific, as TPEN [tetrakis(2pyridylmethyl)ethylenediamine], a chelator of free zinc, eliminated the uptakedependent fluorescence.

To further explore the localization of intracellularly imported zinc, we used FluoZin-3 loading and two-photon microscopy. The FluoZin-3-loaded hippocampal neurons were immunostained for cytochrome $C$ (cyt $C$, as a marker of mitochondria, a site of potential zinc accumulation) and counterstained with DAPI (to visualize nuclei). Nontreated control cells displayed baseline levels of cytoplasmic zinc present in the soma, axon, and dendrites. tPA treatment by itself did not affect the basal levels of zinc import (although there was consistently a minor decrease in FluoZin-3 fluorescence detected with tPA-alone controls). Cyt $C$ staining (Fig. 5B, visualized as red) appeared normal in these cells, as mitochondria were dispersed throughout the soma. Treatment with zinc increased the amount of FluoZin-3 fluorescence in the cells, in agreement with our previous data (supplemental Fig. 3, available at www. jneurosci.org as supplemental material; Fig. 4; Siddiq and Tsirka, 2004), and induced colocalization with cyt $C$, visualized as yellow (arrows). This colocalization presented in many cells within the soma. When cells were incubated with zinc and tPA, the staining was more punctate (arrows), spread throughout the cell and included areas of the axons and dendrites, possibly indicative of vesicular distribution of zinc.

To determine the physiological significance of tPA on zinc import wt and $\mathrm{tPA}^{-1-}$ hippocampal slice cultures were prepared and treated with $50 \mu \mathrm{M}$ zinc. Zinc uptake was analyzed using the marker FluoZin-3 (Fig. 5C) and the fluorescence uptake was quantified. The $\mathrm{CA} 3$ region in particular took up the most zinc. Higher zinc uptake was measured in the wt slice compared with the $\mathrm{tPA}^{-1-}$ slice (the $\mathrm{tPA}^{-1-}$ slices had $\sim 60 \%$ of the fluorescence of the wt slices) supporting the evidence that tPA facilitates zinc import.

ZIP4 functions as a carrier protein to import zinc by binding it on the cell surface and internalizing it using endocytosis. Zincbound ZIP4 traffics to recycling endosomes, releases the zinc, and 
A

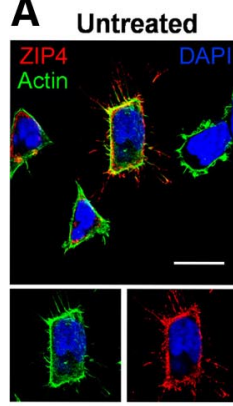

$50 \mu \mathrm{M} Z \mathrm{Zn}$
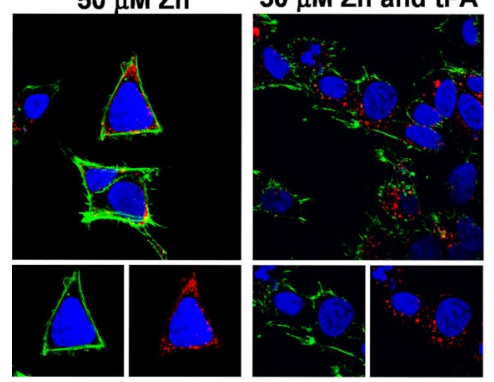

B

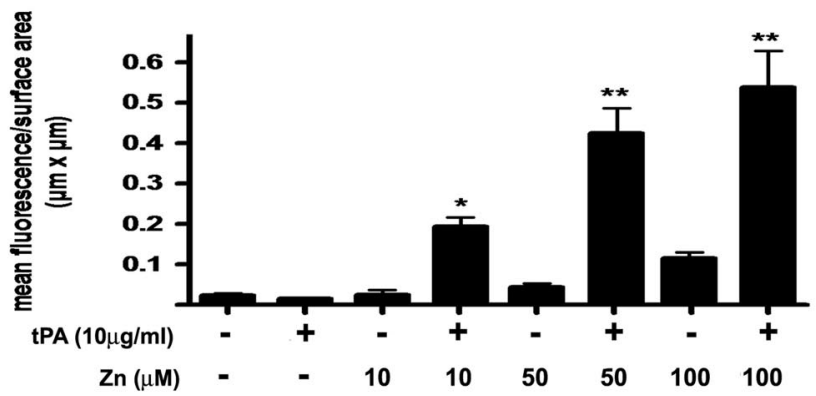

C

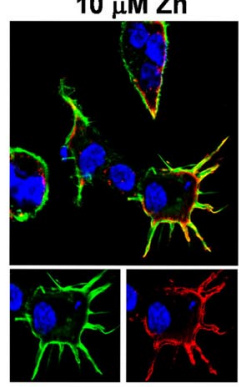

$100 \mu \mathrm{M} Z \mathrm{Zn}$

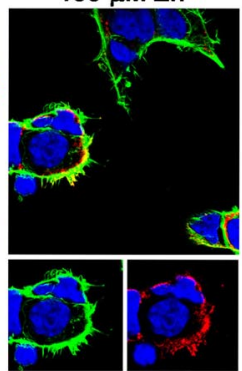

$10 \mu \mathrm{M} Z n$ and tPA

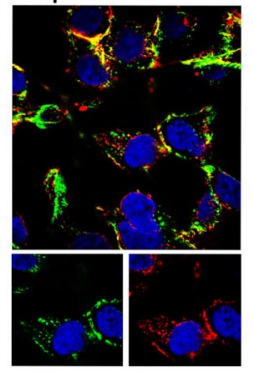

$100 \mu \mathrm{M} \mathrm{Zn}$ and tPA

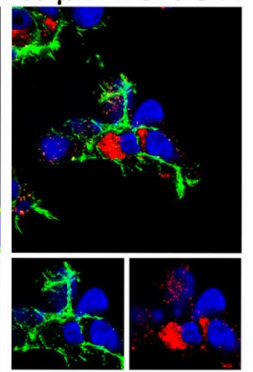

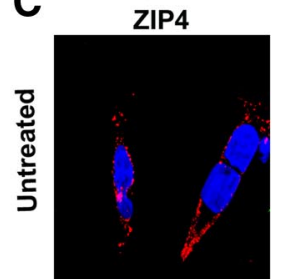
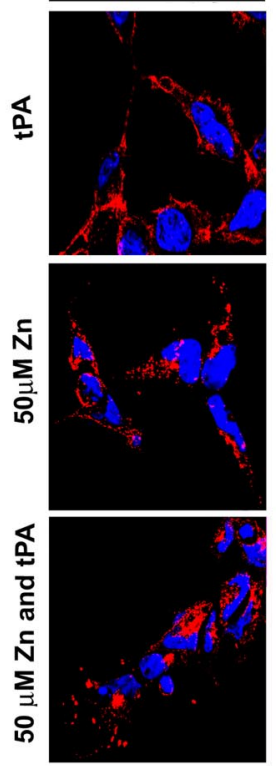

LAMP-1
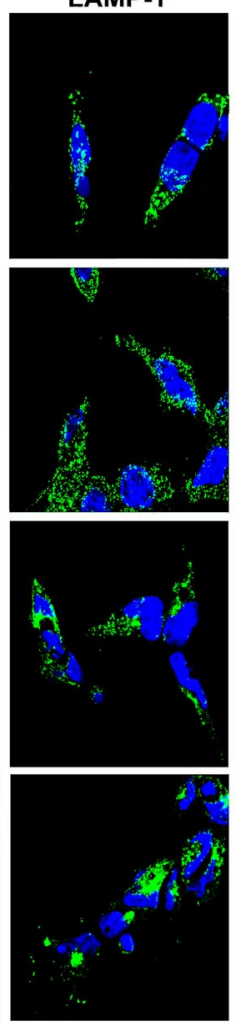

Merge
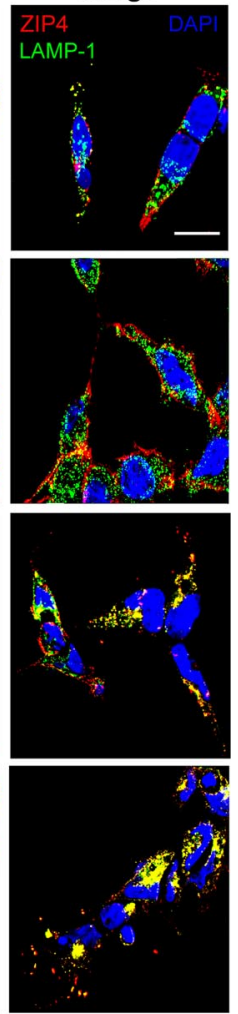

Figure 6. TPA increases vesicular uptake of ZIP4 into lysosomes in ZIP4-expressing HEK293 cells. Confocal images of mZIP4-expressing HEK293 cells incubated with increasing concentrations of zinc in the presence or absence of PA. A, The presence of $\mathrm{mZIP4}$ was visualized with an anti-HA antibody (red); actin was visualized using phalloidin (green), and nuclei were marked with DAPI (blue). $B$, Fluorescent intensity of intracellular ZIP4 was quantified using the LSM imaging software. The experiments were repeated at least five times and 30 cells quantified for each condition. Error bars represent SEM, where ${ }^{*} p<0.05,{ }^{* * *} p<0.001$ by ANOVA followed by Bonferroni's post hoc test. Scale bar, $20 \mu \mathrm{m}$. C, mZIP4 cells were incubated with $50 \mu \mathrm{m}$ zinc or zinc and tPA. The cells were stained for ZIP4 (red) using the anti-HA antibody, and the lysosomal marker LAMP-1 (green). $n=3$ individual experiments.

then returns to the plasma membrane. ZIP4 trafficking is regulated by unknown mechanisms that sense zinc levels; ZIP4 cycling to the plasma membrane is enhanced in zinc deficiency (Kim et al., 2004). We next examined whether tPA affects zincloaded ZIP4 trafficking, using the HA-ZIP4-expressing HEK293 cells. Under control conditions, ZIP4 was observed at the plasma membrane (red, Fig. 6A) at or near cortical actin (green), as shown in representative images (quantification is described in Fig. $6 B$ ). A similar localization was observed when either $\mathrm{tPA}$ or a low concentration $(10 \mu \mathrm{M})$ of zinc was added. However, addition of both tPA and $10 \mu \mathrm{M}$ zinc caused a tenfold increase in endocytosis, resulting in internalization of a significant fraction of the peripheral ZIP4 into cytoplasmic vesicles, presumably early endosomes, while the remaining ZIP4 plasma membrane staining became punctate. Small amounts of endocytosis were observed when 50 or $100 \mu \mathrm{M}$ zinc was added to the cultures; in contrast, addition of tPA with $50 \mu \mathrm{M}$ zinc resulted in complete endocytosis of ZIP4 into vesicles, and addition of tPA with $100 \mu \mathrm{M}$ zinc resulted in accumulation of the endocytosed ZIP4 into perinuclear recycling endosomes. Thus, tPA increases zinc-loaded ZIP4 endocytosis, facilitating zinc entry, and directing the entering zinc into vesicles, rather than into the cytoplasm as occurs when it enters through $\mathrm{Ca}-\mathrm{A} / \mathrm{K}$, voltage-sensitive calcium channels (VSCC).
It has been suggested that during seizures, the high levels of zinc released are taken back up and sequestered in lysosomal vesicles (Hwang et al., 2008), as a byproduct of ZIP4 degradation by lysosomal and proteosomal pathways (Mao et al., 2007). This led us to evaluate whether tPA enhanced the sequestration of zinc and mZIP4 to lysosomes as a method of protection against zinc toxicity. Immunostaining against mZIP4 revealed minimal localization with the lysosomal marker LAMP-1 in control, untreated cells and in cells treated with tPA alone (Fig. 6C). When the cells were treated with $50 \mu \mathrm{M}$ zinc, there was an increase in MZIP4 and LAMP-1 colocalization; significant colocalization between mZIP4 and LAMP-1 was also evident in cells treated with zinc and tPA (Fig. $6 C)$. These data suggest that in addition to the physical interaction between the zinc transporter (ZIP4) and tPA (Figs. 2, 3), the presence of tPA both enhanced the import of zinc into the cells (Figs. 4, 5) and affected the localization of the mZIP4 transporter, which trafficked from the cell surface to lysosomal compartments.

tPA facilitation of zinc import by ZIP4 shifts intracellular signaling networks toward prosurvival pathways, providing protection against zinc toxicity

Very little is known about the signaling pathways that may be involved or affected by ZIP4/zinc trafficking. However, ZIP family 


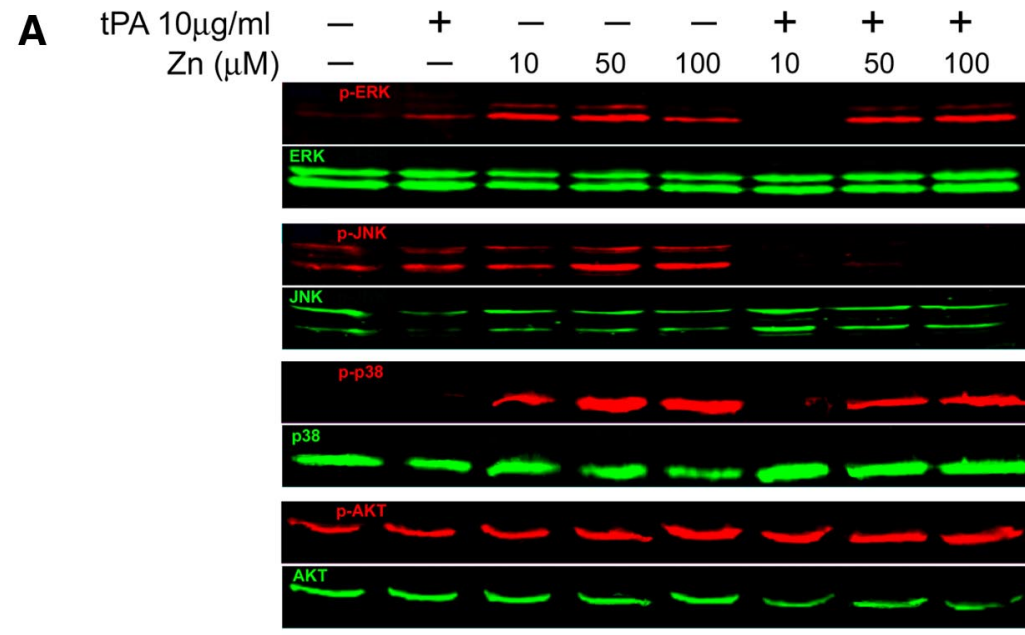

B Phosphorylated ERK

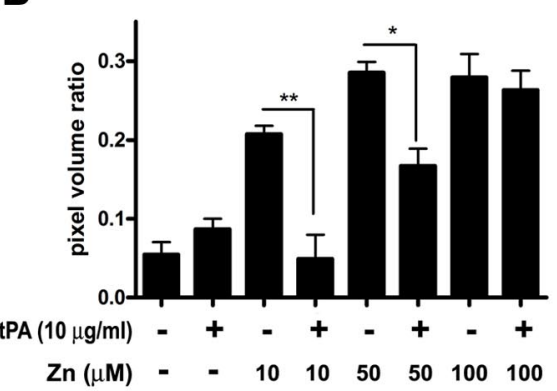

Phosphorylated P38

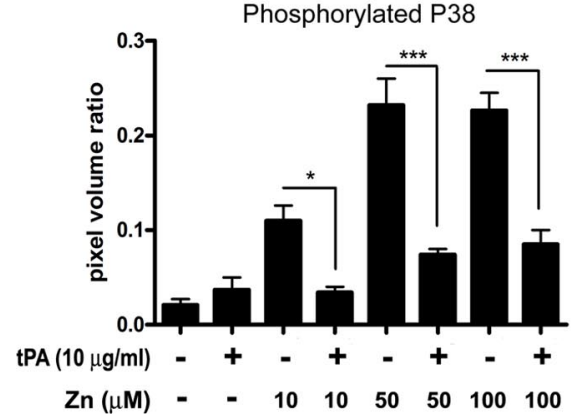

Phosphorylated JNK

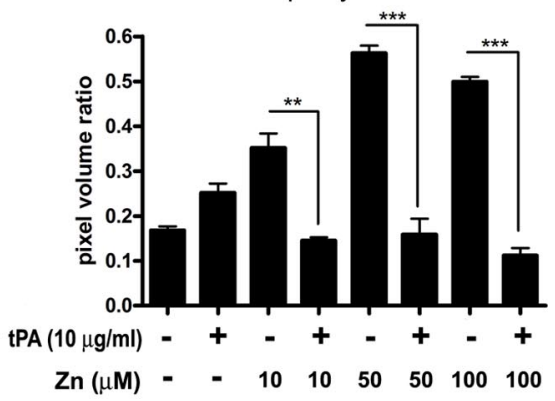

Phosphorylated AKT

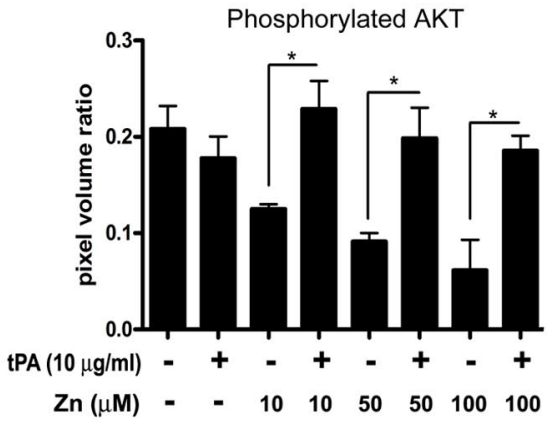

Figure 7. Proapoptotic signals are altered in the presence of tPA. A, Quantitative immunoblot analyses of proteins involved in cell death due to zinc toxicity were performed on HEK cell lysates. mZIP4 HEK cells were treated with various concentrations of zinc with or without tPA and the expression of ERK, p-ERK, JNK, p-JNK, p38, p-p38, AKT, and p-AKT assessed. B, Quantitative measurements of kinase phosphorylation were performed using the 0dyssey 2.1 software and the data were plotted as a ratio of the pixel volume of the phosphorylated kinase over the pixel volume of total kinase. For statistical analysis, zinc treatment was compared with zinc plus tPA treatment. Error bars represent SEM, where ${ }^{*} p<0.05,{ }^{* *} p<0.01,{ }^{* * *} p<0.001$ by ANOVA followed by Bonferroni's post hoc test ( $n=3$ independent experiments).

members have been associated with intracellular signaling changes: ZIP1 internalization has been linked to changes in the actin cytoskeleton (Khadeer et al., 2005), ZIP7 to tyrosine kinase activation in cancer cells (Hogstarnd et al., 2009), and ZIP13 to growth factor/ BMP signaling (Fukada et al., 2008); these reports suggest that ZIP4 could mediate global changes in cellular responses. To explore this possibility in the context of zinc toxicity, we probed several signaling pathways known to be involved in pro- and antiapoptotic outcomes for neurons. The mitogen-activated protein kinase (MAPK) pathway (ERK1/2, p38 kinase and c-Jun N terminal kinase (JNK)) has been shown to contribute to neuronal cell death in a variety of in vitro and in vivo neurotoxicity models (Murray et al., 1998; Jeon et al., 2000; Eom et al., 2001; Koh, 2001; Seo et al., 2001; Jiang et al., 2005; Namiki et al., 2007). Under resting conditions, phospho-p38 (p-p38) and p-ERK were barely detectable in mZIP4-expressing HEK293 cells, and modest amounts of p-JNK were observed (Fig. 7A). Upon zinc addition, p-ERK, p-JNK, and p-p38 increased substantially, while p-AKT stayed the same. However, when tPA was added along with zinc, most of the p-ERK, p-JNK, and p-p38 zinc-induced increases were blunted or eliminated, and p-AKT modestly increased (Fig. 7B). Together, zinc exposure seemed to trigger proapoptotic pathways that were ameliorated by the presence of tPA. These data suggested that tPA may protect against zinc toxicity through regulated import of zinc that leads to the sequestration into vesicles and modulation of the activation of MAPKs involved with the apoptotic process associated with zinc toxicity.

\section{Discussion}

We report here that excitotoxic stimulation of neurons upregulates the expression of the zinc transporter ZIP4 in the mouse hippocampus, and that ZIP4 physically interacts with tPA, enhances the import of zinc into cells, and promotes a prosurvival state. In our previous work, we had inhibited general endocytosis as well as the low-density lipoprotein receptor-related protein (LRP, which acts as a scavenger receptor for tPA), and determined that these mechanisms were not responsible for zinc import in the presence of tPA.

During the course of this study we observed that the expression of the ZIP4 gene in the hippocampus was increased after kainate injection. This is an interesting finding since the ZIP4 protein is recognized to be an important transporter for dietary zinc absorption in the intestine (Eide, 2006); Dufner-Beattie et al., 2003). In the intestines and liver ZIP4 mRNA is upregulated in conditions of zinc deficiency and the ZIP4 protein is transported to the plasma membrane. When zinc is present, ZIP4 is regulated in various ways: at the mRNA level, at the plasma membrane by endocytosis though recycling endosomes, and by ubiquitination and subsequent degradation (Kim et al., 2004; Mao et al., 2007). In another study using whole brain tissue, little to no ZIP4 expression (Dufner-Beattie et al., 2003) was observed, however different subregions of the brain were not examined. As hippocampal neurons are postmitotic, it is feasible that following seizures, the levels of zinc are regulated differently than in replicating cells. Another possibility is that since tPA partly acts as a zinc chelator, its presence may mimic zinc deficiency, which would then trigger an upregulation of ZIP4 on the surface of cells.

One potential caveat of our experiments is the fact that the concentration of tPA used was quite high $(10 \mu \mathrm{g} / \mathrm{ml})$. The rationale behind using such a concentration is that it was previously 
used to show that zinc toxicity is eliminated by the presence of tPA (Kim et al., 1999; Siddiq and Tsirka, 2004). Moreover, as tPA is thought to be secreted from the presynaptic neurons into the synaptic cleft, it is possible that the local concentration of tPA in the synaptic cleft is much higher than the concentration used in our work. In experiments modeling secretion of tPA into the extracellular/synaptic space other investigators have used concentrations up to $60 \mu \mathrm{g} / \mathrm{ml}$ (Nicole et al., 2001; Pang et al., 2004).

Utilization of tPA domain deletion mutants indicated that zinc binds to tPA through the growth factor domain. Not all import was abolished, however, due to other routes of zinc entry into the cells; in neurons such routes of entry include the $\mathrm{Ca}^{2+}$ permeable AMPA/KA channels, Zn exchangers, and NMDA receptors (Weiss et al., 1993, 2000; Siddiq and Tsirka, 2004). It is possible that zinc binds to the growth factor domain of tPA and that ZIP4 interacts with the kringle domain of tPA through its histidine-rich cluster in the cytoplasmic region (Mao et al., 2007), and that through these interactions tPA facilitates zinc import into cells. Our data would also suggest that the catalytic domain/ activity for tPA is not critical for ZIP binding, as is also the case for zinc import. Following zinc release from presynaptic boutons, zinc may initially bind to and is partially chelated by the growth factor domain of tPA, this consequently induces an increase of ZIP4 at the plasma membrane. Subsequently, zinc-bound-tPA interacts with ZIP4 (bound or not bound to zinc) through the kringle domain of tPA with the extracellular region of the transporter facilitating zinc and ZIP4 vesicular internalization. Although it is not necessary for zinc to be imported into neurons for ZIP4 to be protective in vivo, since the increase in ZIP4 expression appears to be primarily neuronal, it is likely that this zinc import renders ZIP4 neuroprotective.

Under conditions of increased cytosolic levels of zinc, mitochondria have been demonstrated to function as possible zincaccumulating organelles (Sensi et al., 2003). Other studies have linked zinc-storage to late endosomes/lysosomes in neuron synaptic vesicles (Danscher and Stoltenberg, 2005; Smith and Lee, 2007; Smith et al., 2007). Hwang et al. (2008) demonstrated that in the presence of kainate and high concentrations of zinc, the majority of zinc-containing vesicles in hippocampal neurons are indeed lysosomes. This led us to consider whether the interaction between tPA, zinc and ZIP4 mitigates toxicity by altering zinc homeostasis, including the sequestration of zinc to lysosomal vesicles subsequent to seizures. Consistent with the data from Hwang et al., ZIP4 containing vesicles colocalized with the lysosomal marker LAMP-1 demonstrating that ZIP4, and presumably zinc, is sequestered to lysosomes. Zinc toxicity is associated with high intracellular concentrations of unbound chelatable zinc. It is conceivable that lysosomes act to harbor zinc and that the intracellular release of zinc from lysosomes is regulated by the binding of zinc to tPA. In addition, tPA can chelate zinc (Siddiq and Tsirka, 2004), although the concentration of tPA required to chelate all secreted zinc would be prohibitively high.

Interestingly, perturbation of the actin cytoskeleton was observed upon tPA treatment, which points toward an active response of the cells to the high zinc challenge. The protein kinases that were analyzed, ERK, JNK and p38, become phosphorylated and activated under excitotoxic conditions. Similar findings were observed when mZIP4-transfected HEK cells were incubated with increasing concentrations of zinc, although when tPA was present, there was a significant reduction of the phosphorylated forms of the kinases.

Mice deficient in the ZnT3 transporter lack vesicular zinc, a finding that would infer that neurons would not be able to secrete zinc once stimulated. However, zinc accumulates in ZnT3-null mice after injection with kainate either as a result of zinc released from internal stores, or because neurons do take up zinc (Lee et al., 2000). ZIP4 may function as an additional transporter involved in neuronal uptake of zinc, active even when vesicular zinc is absent. It is possible that under these conditions zinc is being released by surrounding cells and that it is taken up via various routes of entry, such as ZIP4, $\mathrm{Ca}^{2+}$-permeable AMPA/KA channels, $Z n$ exchangers, and NMDA receptors. Alternatively the neurons may possess an internal zinc release mechanism from intracellular compartments (Lee et al., 2000). It is feasible that under pathological conditions, neuronal stress could result in the zinc release observed in the ZnT3-null mice. Our data revealed that ZIP4 was expressed at low basal levels under normal conditions, but when an insult occurred, ZIP4 expression increased in the hippocampus. It is possible that in the absence of vesicular zinc, ZIP4 is upregulated at the cell surface to compensate for the lack of synaptic zinc. Zinc taken up by neurons via ZIP4 may not be entering synaptic vesicles but instead sequestered to zincstorage compartments.

In conclusion, our results have shown that tPA facilitates the partial sequestration of zinc into lysosomal compartments via ZIP4, thereby regulating the intracellular concentrations of zinc and acting in a neuroprotective manner by modulating intracellular signaling events that could lead to cell death.

\section{References}

Andrade-Gordon P, Strickland S (1986) Interaction of heparin with plasminogen activators and plasminogen: effects on the activation of plasminogen. Biochemistry 25:4033-4040.

Belloni-Olivi L, Marshall C, Laal B, Andrews GK, Bressler J (2009) Localization of zipl and zip4 mRNA in the adult rat brain. J Neurosci Res 87:3221-3230.

Choi DW, Koh JY (1998) Zinc and brain injury. Annu Rev Neurosci 21:347-375.

Cornford EM, Nguyen EV, Landaw EM (2000) Acute upregulation of blood-brain barrier glucose transporter activity in seizures. Am J Physiol Heart Circ Physiol 279:H1346-H1354.

Coulter D (2000) Mossy fiber zinc and temporal lobe epilepsy: pathological association with altered "epileptic" gamma-aminobutyric acid A receptors in dentate granule cells. Epilepsia 41 [Suppl 6]:S96-S99.

Danscher G, Stoltenberg M (2005) Zinc-specific autometallographic in vivo selenium methods: tracing of zinc-enriched (ZEN) terminals, ZEN pathways, and pools of zinc ions in a multitude of other ZEN cells. J Histochem Cytochem 53:141-153.

Dufner-Beattie J, Wang F, Kuo YM, Gitschier J, Eide D, Andrews GK (2003) The acrodermatitis enteropathica gene ZIP4 encodes a tissue-specific, zinc-regulated zinc transporter in mice. J Biol Chem 278:33474-33481.

Eide DJ (2006) Zinc transporters and the cellular trafficking of zinc. Biochim Biophys Acta 1763:711-722.

Eom SJ, Kim EY, Lee JE, Kang HJ, Shim J, Kim SU, Gwag BJ, Choi EJ (2001) $\mathrm{Zn}(2+)$ induces stimulation of the c-Jun N-terminal kinase signaling pathway through phosphoinositide 3-kinase. Mol Pharmacol 59:981-986.

Finney L, Mandava S, Ursos L, Zhang W, Rodi D, Vogt S, Legnini D, Maser J, Ikpatt F, Olopade OI, Glesne D (2007) X-ray fluorescence microscopy reveals large-scale relocalization and extracellular translocation of cellular copper during angiogenesis. Proc Natl Acad Sci U S A 104:2247-2252.

Frederickson CJ, Hernandez MD, Goik SA, Morton JD, McGinty JF (1988) Loss of zinc staining from hippocampal mossy fibers during kainic acid induced seizures: a histofluorescence study. Brain Res 446:383-386.

Frederickson CJ, Giblin LJ, Krezel A, McAdoo DJ, Mueller RN, Zeng Y, Balaji RV, Masalha R, Thompson RB, Fierke CA, Sarvey JM, de Valdenebro M, Prough DS, Zornow MH (2006a) Concentrations of extracellular free zinc $(\mathrm{pZn}) \mathrm{e}$ in the central nervous system during simple anesthetization, ischemia and reperfusion. Exp Neurol 198:285-293.

Frederickson CJ, Giblin LJ 3rd, Balaji RV, Rengarajan B, Masalha R, Frederickson CJ, Zeng Y, Lopez EV, Koh JY, Chorin U, Besser L, Hershfinkel M, Li Y, Thompson RB, Krezel A (2006b) Synaptic release of zinc from 
brain slices: factors governing release, imaging, and accurate calculation of concentration. J Neurosci Methods 154:19-29.

Fukada T, Civic N, Furuichi T, Shimoda S, Mishima K, Higashiyama H, Idaira Y, Asada Y, Kitamura H, Yamasaki S, Hojyo S, Nakayama M, Ohara O, Koseki H, Dos Santos HG, Bonafe L, Ha-Vinh R, Zanki A, Unger S, Kraenzlin ME, et al. (2008) The zinc transporter SLC39A13/ZIP13 is required for connective tissue development; its involvement in BMP/TGFbeta signaling pathways. PLoS One 3:e3642.

Glesne D, Vogt S, Maser J, Legnini D, Huberman E (2006) Regulatory properties and cellular redistribution of zinc during macrophage differentiation of human leukemia cells. J Struct Biol 155:2-11.

Hogstrand C, Kille P, Nicholson RI, Taylor KM (2009) Zinc transporters and cancer: a potential role for ZIP7 as a hub for tyrosine kinase activation. Trends Mol Med 15:101-111.

Hwang JJ, Lee SJ, Kim TY, Cho JH, Koh JY (2008) Zinc and 4-hydroxy-2nonenal mediate lysosomal membrane permeabilization induced by $\mathrm{H} 2 \mathrm{O} 2$ in cultured hippocampal neurons. J Neurosci 28:3114-3122.

Jeon SH, Kim YS, Bae CD, Park JB (2000) Activation of JNK and p38 in rat hippocampus after kainic acid induced seizure. Exp Mol Med 32:227-230.

Jiang W, Van Cleemput J, Sheerin AH, Ji SP, Zhang Y, Saucier DM, Corcoran ME, Zhang X (2005) Involvement of extracellular regulated kinase and p38 kinase in hippocampal seizure tolerance. J Neurosci Res 81:581-588.

Khadeer MA, Sahu SN, Bai G, Abdulla S, Gupta A (2005) Expression of the zinc transporter ZIP1 in osteoclasts. Bone 37:296-304.

Kim BE, Wang F, Dufner-Beattie J, Andrews GK, Eide DJ, Petris MJ (2004) $\mathrm{Zn}^{2+}$-stimulated endocytosis of the MZIP4 zinc transporter regulates its location at the plasma membrane. J Biol Chem 279:4523-4530.

Kim YH, Park JH, Hong SH, Koh JY (1999) Nonproteolytic neuroprotection by human recombinant tissue plasminogen activator. Science 284: 647-650.

Klitenick MA, Frederickson CJ, Manton WI (1983) Acid-vapor decomposition for determination of zinc in brain tissue by isotope dilution mass spectrometry. Anal Chem 55:921-923.

Koh JY (2001) Zinc and disease of the brain. Mol Neurobiol 24:99-106.

Kornblum HI, Araujo DM, Annala AJ, Tatsukawa KJ, Phelps ME, Cherry SR (2000) In vivo imaging of neuronal activation and plasticity in the rat brain by high resolution positron emission tomography (microPET). Nat Biotechnol 18:655-660.

Lee JY, Cole TB, Palmiter RD, Koh JY (2000) Accumulation of zinc in degenerating hippocampal neurons of ZnT3-null mice after seizures: evidence against synaptic vesicle origin. J Neurosci 20:RC79.

Liuzzi JP, Cousins RJ (2004) Mammalian zinc transporters. Annu Rev Nutr 24:151-172.

Lothman EW, Stringer JL, Bertram EH (1992) The dentate gyrus as a control point for seizures in the hippocampus and beyond. Epilepsy Res [Suppl] 7:301-313.

Mao X, Kim BE, Wang F, Eide DJ, Petris MJ (2007) A histidine-rich cluster mediates the ubiquitination and degradation of the human zinc transporter, hZIP4, and protects against zinc cytotoxicity. J Biol Chem 282: 6992-7000.

Millan E, Abou-Khalil B, Delbeke D, Konrad P (2001) Frontal localization of absence seizures demonstrated by ictal positron emission tomography. Epilepsy Behav 2:54-60.

Mirrione MM, Schiffer WK, Siddiq M, Dewey SL, Tsirka SE (2006) PET imaging of glucose metabolism in a mouse model of temporal lobe epilepsy. Synapse 59:119-121.

Murray B, Alessandrini A, Cole AJ, Yee AG, Furshpan EJ (1998) Inhibition of the p44/42 MAP kinase pathway protects hippocampal neurons in a cell-culture model of seizure activity. Proc Natl Acad Sci U S A 95: 11975-11980.

Namiki K, Nakamura A, Furuya M, Mizuhashi S, Matsuo Y, Tokuhara N, Sudo T, Hama H, Kuwaki T, Yano S, Kimura S, Kasuya Y (2007) Involvement of p38alpha in kainate-induced seizure and neuronal cell damage. J Recept Signal Transduct Res 27:99-111.

Nicole O, Docagne F, Ali C, Margaill I, Carmeliet P, MacKenzie ET, Vivien D, Buisson A (2001) The proteolytic activity of tissue-plasminogen activator enhances NMDA receptor-mediated signaling. Nat Med 7:59-64.

Pang PT, Teng HK, Zaitsev E, Woo NT, Sakata K, Zhen S, Teng KK, Yung
WH, Hempstead BL, Lu B (2004) Cleavage of proBDNF by tPA/plasmin is essential for long-term hippocampal plasticity. Science 306:487-491.

Pei YQ, Koyama I (1986) Features of seizures and behavioral changes induced by intrahippocampal injection of zinc sulfate in the rabbit: a new experimental model of epilepsy. Epilepsia 27:183-188.

Qian Z, Gilbert ME, Colicos MA, Kandel ER, Kuhl D (1993) Tissueplasminogen activator is induced as an immediate-early gene during seizure, kindling and long-term potentiation. Nature 361:453-457.

Rogove AD, Tsirka SE (1998) Neurotoxic responses by microglia elicited by excitotoxic injury in the mouse hippocampus. Curr Biol 8:19-25.

Sensi SL, Ton-That D, Sullivan PG, Jonas EA, Gee KR, Kaczmarek LK, Weiss $\mathrm{JH}$ (2003) Modulation of mitochondrial function by endogenous $\mathrm{Zn}^{2+}$ pools. Proc Natl Acad Sci U S A 100:6157-6162.

Seo SR, Chong SA, Lee SI, Sung JY, Ahn YS, Chung KC, Seo JT (2001) $\mathrm{Zn}^{2+}$-induced ERK activation mediated by reactive oxygen species causes cell death in differentiated PC12 cells. J Neurochem 78:600-610.

Serrano L, Dominguez JE, Avila J (1988) Identification of zinc-binding sites of proteins: zinc binds to the amino-terminal region of tubulin. Anal Biochem 172:210-218.

Siao CJ, Tsirka SE (2002) Tissue plasminogen activator mediates microglial activation via its finger domain through annexin II. J Neurosci 22: 3352-3358.

Siconolfi LB, Seeds NW (2001) Mice lacking tPA, uPA, or plasminogen genes showed delayed functional recovery after sciatic nerve crush. J Neurosci 21:4348-4355.

Siddiq M (2003) Zinc and tissue plasminogen activator in the mammalian central nervous system. PhD thesis, Stony Brook University.

Siddiq MM, Tsirka SE (2004) Modulation of zinc toxicity by tissue plasminogen activator. Mol Cell Neurosci 25:162-171.

Sloviter RS, Dichter MA, Rachinsky TL, Dean E, Goodman JH, Sollas AL, Martin DL (1996) Basal expression and induction of glutamate decarboxylase and GABA in excitatory granule cells of the rat and monkey hippocampal dentate gyrus. J Comp Neurol 373:593-618.

Smith AP, Lee NM (2007) Role of zinc in ALS. Amyotroph Lateral Scler 8:131-143.

Smith DG, Cappai R, Barnham KJ (2007) The redox chemistry of the Alzheimer's disease amyloid beta peptide. Biochim Biophys Acta 1768: 1976-1990.

Suh SW, Jo SM, Vajda Z, Danscher G (2001) Adrenalectomy causes loss of zinc ions in zinc-enriched (ZEN) terminals and decreases seizure-induced neuronal death. Brain Res 895:25-32.

Sutula T, Harrison C, Steward O (1986) Chronic epileptogenesis induced by kindling of the entorhinal cortex: the role of the dentate gyrus. Brain Res 385:291-299.

Takimoto M, Mao P, Wei G, Yamazaki H, Miura T, Johnson AC, Kuzumaki N (1999) Molecular analysis of the GCF gene identifies revisions to the cDNA and amino acid sequences(1). Biochim Biophys Acta 1447: 125-131.

Timofeeva O, Nadler JV (2006) Facilitation of granule cell epileptiform activity by mossy fiber-released zinc in the pilocarpine model of temporal lobe epilepsy. Brain Res 1078:227-234.

Tsirka SE, Gualandris A, Amaral DG, Strickland S (1995) Excitotoxininduced neuronal degeneration and seizure are mediated by tissue plasminogen activator. Nature 377:340-344.

Van Zonneveld AJ, Veerman H, MacDonald M, van Mourik J, Pannekoek H (1986) Structure and function of human tissue-type plasminogen activator (+-PA). J Cell Biochem 32:169-178.

Vogt S, Maser J, Jacobsen C (2003) Data analysis for X-ray fluorescence imaging. J Phys IV 104:617-622.

Walker MC, Ruiz A, Kullmann DM (2002) Do mossy fibers release GABA? Epilepsia 43 [Suppl 5]:196-202.

Wang F, Kim BE, Dufner-Beattie J, Petris MJ, Andrews G, Eide DJ (2004) Acrodermatitis enteropathica mutations affect transport activity, localization and zinc-responsive trafficking of the mouse ZIP4 zinc transporter. Hum Mol Genet 13:563-571.

Weiss JH, Hartley DM, Koh JY, Choi DW (1993) AMPA receptor activation potentiates zinc neurotoxicity. Neuron 10:43-49.

Weiss JH, Sensi SL, Koh JY (2000) Zn(2+): a novel ionic mediator of neural injury in brain disease. Trends Pharmacol Sci 21:395-401. 